\title{
Ethinyl Estradiol
}

National Cancer Institute

\section{Source}

National Cancer Institute. Ethinyl Estradiol. NCI Thesaurus. Code C486.

A semisynthetic estrogen. Ethinyl estradiol binds to the estrogen receptor complex and enters the nucleus, activating DNA transcription of genes involved in estrogenic cellular responses. This agent also inhibits 5-alpha reductase in epididymal tissue, which lowers testosterone levels and may delay progression of prostatic cancer. In addition to its antineoplastic effects, ethinyl estradiol protects against osteoporosis. In animal models, short-term therapy with this agent has been shown to provide long-term protection against breast cancer, mimicking the antitumor effects of pregnancy. (NCI04) 